RASĀYAN J. Chem.

Vol. 12 | No. 4 |1693 - 1700| October - December | 2019 ISSN: 0974-1496 | e-ISSN: 0976-0083 | CODEN: RJCABP

RJC http://www.rasayanjournal.com http://www.rasayanjournal.co.in

\title{
SIMULTANEOUS ASSAYS OF SULFAMETHOXAZOLE AND TRIMETHOPRIM IN SUSPENSION DOSAGE FORM BY THREE ANALYTICAL METHODS OF UV SPECTROPHOTOMETRY
}

\author{
Muchlisyam*, E.S.B Raesa, R. Dathita and S.P. Richa \\ Department of Chemistry, Faculty of Pharmacy, Universitas Sumatera Utara, Kampus USU, \\ Padang Bulan, Medan, 20155, Indonesia. \\ *E-mail: muchlisyam@usu.ac.id
}

\begin{abstract}
The research goal is to apply and validate of the ratio of the absorption method (RA), Area Under Curve Method (AUC) and Chemometric spectrophotometry methods (CMS) for simultaneous assays of Sulfamethoxazole and Trimethoprim combined in a suspension. Measurements of absorption for RA method in the wavelength at $249 \mathrm{~nm}$ and $258 \mathrm{~nm}$, the AUC method absorption measurement in the wavelength at 257-267 nm for Sulfamethoxazole and wavelength 283-293 nm for Trimethoprim and absorption measurements to for Sulfamethoxazole and Trimethoprim in CMS methods performed on a wavelength in the range of $230-310 \mathrm{~nm}$ with intervals of $2 \mathrm{~nm}$. The RA method has linearity (3.3-8.9) $\mu \mathrm{g} / \mathrm{ml}$, accuracy $=99.89 \%$, and precision $=0.20 \%$ for Sulfamethoxazole and linearity $=(9.2-25.2)$ $\mu \mathrm{g} / \mathrm{ml}$, accuracy $=101.28 \%$, and precision $=0.71 \%$ for Trimethoprim, while the AUC method has an accuracy of $99.34 \%$, and precision $=0.44 \%$ for Sulfamethoxazole, and accuracy $=100.05 \%$, precision $=1.16 \%$ for Trimethoprim whereas Chemometric method has an accuracy $=100.69 \%$, precision $=0.43 \%$ for Sulfamethoxazole and accuracy $=101.25 \%$, precision $=0.43 \%$ for Trimethoprim. The three analytical methods of spectrophotometry have validation requirements according to ICH guidelines (2005) and the level of Sulfamethoxazole and Trimethoprim met Indonesian pharmacopeia (2014) requirements.
\end{abstract}

Keywords: Three Methods, Spectrophotometry, Sulfamethoxazole, Trimethoprim, Validation.

(C) RASĀYAN. All rights reserved

\section{INTRODUCTION}

Cotrimoxazole is a combination of sulfamethoxazole (SMZ) and trimethoprim (TMP), the combination has good bactericidal activity by inhibiting two-stage nucleic acid biosynthesis and synergistic effects and reducing the danger of resistance compared to trimethoprim or sulfamethoxazole mono-therapy singly. ${ }^{1,2}$ Assay of SMZ and TMP in a single form can be determined with an ultraviolet spectrophotometry method where the SMZ has a maximum absorption in the wavelength at $257 \mathrm{~nm}$ and TMP in the wavelength at $287 \mathrm{~nm}^{3-5}$

Some combination of the spectrophotometric method with mathematical software, among others: chemometric methods, intersection methods, q-absorbance ratio spectrophotometric method, the area under a curve, multivariate calibration and mean centering ratio spectra such as to the determination of betamethasone valerate and neomycin sulfate, prednisolone and 5-aminosalicylic acid, carvedilol and hydrochlorothiazide; paracetamol, ibuprofen, and caffeine, etilefrine $\mathrm{HCl}$ with chlorpheniramine. ${ }^{6-17}$ The research goal is to application and validation of, AUC method, CMS methods, and RA method for simultaneous assays of SMZ and TMP combined in suspension with methanol as a solvent.

\section{EXPERIMENTAL}

Material and Methods

Ultraviolet-visible spectrophotometer (Shimadzu 1800, Japan), a set of Personal Computers (PC) equipped with UV-Probe 2.42 software, Minitab version 16.2.4.4 software (Toshiba, Japan) Methanol E. Merck From PT Rudang Jaya, Medan, Indonesia, standard of SMZ, standard of TMP from Health

Rasayan J. Chem., 12(4), 1693-1700(2019)

http://dx.doi.org/10.31788/RJC.2019.1245428

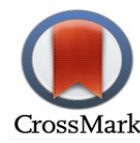


RASĀYAN J. Chem.

Vol. 12 | No. 4 |1693 - 1700| October - December | 2019

Department of Indonesian Government, raw material of SMZ and TMP from Kimia Farma Plant Production, Indonesia, Co-trimoxazole suspension produced locally from PT Sanbe Farma Bandung Indonesia.

\section{Preparation of Stock and Working Solution}

Carefully weighed $25 \mathrm{mg}$ of SMZ and TMP respectively, then put each into a volumetric flask $50 \mathrm{ml}$, dissolved with $50 \%$ methanol solvent and filled to the line mark, then piped $5 \mathrm{ml}$ each into a volumetric flask $25 \mathrm{ml}$, diluted with $50 \%$ methanol to the line mark, so that each solution is obtained with a concentration of $100 \mu \mathrm{g} / \mathrm{ml}^{15}$

\section{Preparation of a Spectrum Absorption Maximum for SMZ and TMP}

Pipette $0.61 \mathrm{ml}$ of SMZ solution and $1.72 \mathrm{ml}$ of TMP solution, then inserted each into the volumetric flask $10 \mathrm{ml}$, diluted with $50 \%$ methanol until the line mark, to obtain a solution of $6.1 \mathrm{mg} / \mathrm{ml} \mathrm{SMZ}$ and $17.2 \mu \mathrm{g} / \mathrm{ml}$ TMP, and then each measured absorption in the wavelength at200-400 $\mathrm{nm} .{ }^{3.15-17}$

\section{Validation Method}

The three analytical methods of UV Spectrophotometry for simultaneous assays of SMZ and TMP was validated as per ICH guidelines. ${ }^{18}$

\section{Accuracy Test}

The Accuracy test method is a range of $80 \%, 100 \%, 120 \%$. The following is the formula for percent recovery. ${ }^{18-20}$

Note:

$$
\text { Percentage recovery }=\frac{c_{F}-c_{A}}{C_{A^{*}}} \times 100 \%
$$

$\mathrm{CF}=$ Concentration after addition

$\mathrm{CA}=$ Sample concentration before the addition

$\mathrm{CA}^{*+}=$ Concentration of the standard substances added.

\section{Precision}

Precision is expressed by the RSD of the data series. To search for RSD using the following formula: ${ }^{17}$

Note:

$$
R S D-\frac{S D}{X} \times 100 \%
$$

$\mathrm{RSD}=$ Relative standard deviation

$\mathrm{SD}=$ Standard deviation

$\mathrm{X}=$ Average data.

\section{Linearity, LOD, and LOQ}

Linearity is the analysis of the relationship between concentration and absorption for each substance so that a linear regression equation and its correlation value are obtained. ${ }^{18-20}$

According to the absorption at the analysis of wavelength, LOD and LOQ are counted as below:

Note:

$$
\begin{aligned}
& S D=\sqrt{\frac{\sum(Y-Y i)^{2}}{n-2}} \\
& L O D=\frac{3.3 \times S D}{\text { Slope }} \\
& L O Q=\frac{10 \times S D}{\text { Slope }}
\end{aligned}
$$

$\mathrm{Y}=$ Amplitude; $\mathrm{a}=$ Slope; $\mathrm{X}=$ Concentration $(\mu \mathrm{g} / \mathrm{ml}) ; \mathrm{b}=$ Constant; $\mathrm{SD} \quad=$ Standard Deviation $;$ Slope= $\mathrm{a}$

\section{Preparation of Sample Suspension}

Pipette $0.62 \mathrm{ml}$ of a drug suspension, then quantitatively on a $50 \mathrm{ml}$ volumetric flask. Dissolved with $50 \%$ methanol, then homogenized with a sonicator for 15 minutes. Filtered, pipette $5 \mathrm{ml}$ of the filtrate and transfer to a $25 \mathrm{ml}$ volumetric flask, filled with $50 \%$ methanol to the line marked and then piped $0.61 \mathrm{ml}$ filtrate and transfer to $10 \mathrm{ml}$ volumetric flask, added $1.6 \mathrm{ml}$ of TMP solution and added 4 drops of 
RASĀYAN J. Chem.

Vol. 12 | No. 4 |1693 - 1700| October - December | 2019

$\mathrm{NH} 4 \mathrm{OH}$ to $\mathrm{pH} 10$, then added with $50 \%$ methanol to mark line to obtain a solution containing $6.1 \mu \mathrm{g} / \mathrm{ml}$ SMZ and $17.2 \mu \mathrm{g} / \mathrm{ml} \mathrm{TMP.}^{15}$.

\section{The Ratio of Absorption Methods}

\section{Construction the Point of Intersection and the Maximum Wavelength Selected}

The absorption spectrum at the intersection point is obtained by overlapping the maximum absorption curve of the SMZ and TMP solution so that it can determine the intersection wavelength and the selected maximum wavelength. ${ }^{7}$

\section{Preparation the Calibration Curve of the RA Method}

The ratio of the maximum absorption spectra was obtained from the concentration, and get the regression line equation. The RA method was validated by calculating accuracy, linearity, precision, LOD, and LOQ. ${ }^{18-20}$

\section{Assays of Sample}

The suspension preparation solution is measured absorption in the wavelength at 200-400 $\mathrm{nm}$, and calculated by UV Probe software 2.42 with a divisor of $17.2 \mu \mathrm{g} / \mathrm{ml} \mathrm{TMP}$ for SMZ and $6.1 \mu \mathrm{g} / \mathrm{ml} \mathrm{SMZ}$ as a divisor for TMP, and the formula to obtain the value is below: ${ }^{7-11}$

$$
\begin{aligned}
& C a: \frac{Q m-Q y}{Q x-Q y} \times \frac{A}{a x 1} \\
& C b: \frac{Q m-Q x}{Q y-Q x} \times \frac{A}{a y 1} \\
& Q m=\frac{A Z}{A 1} \\
& Q x=\frac{a x 2}{a x 1}
\end{aligned}
$$

Note:

$\mathrm{A}=\quad$ Absorption at intersection wavelength

$\mathrm{a} 1$ and $\mathrm{a} 2=$ Absorptivity $\mathrm{x}$ and $\mathrm{y}$ at intersection wavelength

$\mathrm{Ca}=\quad$ Concentration SMZ

$\mathrm{Cb}=$ Concentration TMP

$\mathrm{A} 2=\quad$ Absorption of the sample solution at the maximum wavelength of a component $(\lambda 2)$

$\mathrm{A} 1=\quad$ Absorption of sample solutions at intersection wavelengths of two components $(\lambda 1)$

$\mathrm{ax} 2=$ Absorption of the SMZ working solution at the maximum wavelength of one component $(\lambda 2)$

$\mathrm{ax} 1=$ Absorption of an SMZ working solution at intersection wavelengths of two components $(\lambda 1)$

ay2 $=$ Absorption of the TMP working solution at the maximum wavelength of one component $(\lambda 2)$

ay1 $=$ Absorption of a TMP working solution at intersection wavelengths of two components $(\lambda 1)$.

\section{Area Under the Curve Method}

\section{The AUC spectrum absorptions of SMZ and TMP}

The absorption spectrum of $6.1 \mu \mathrm{g} / \mathrm{ml}$ for SMZ, and the TMP absorption spectrum at concentration is $17.2 \mu \mathrm{g} / \mathrm{ml}$ are overlapped, so the spectrum area is obtained at wavelengths of $257-267 \mathrm{~nm}$ for SMZ and 283-293 $\mathrm{nm}$ for TMP, then the area values are calculated with a divisor of $17.2 \mu \mathrm{g} / \mathrm{ml}$ TMP for SMZ and $6.1 \mu \mathrm{g} / \mathrm{ml} \mathrm{SMZ}$ as a divisor for TMP. ${ }^{16-17}$

\section{Preparation of Calibration Curve}

The value AUC of SMZ spectrum at $257-267 \mathrm{~nm}$ is plotted at a concentration of $(3.3,4.7,6.1,7.5,8.9)$ $\mu \mathrm{g} / \mathrm{ml}$ and value AUC of TMP spectrum at $283-293 \mathrm{~nm}$ are plotted at a concentration of $(9.2,13.2,17.2$, $21.15,25.1) \mu \mathrm{g} / \mathrm{ml}$ to obtain a regression equation. The AUC method was validated with accuracy, linearity, precision, LOD, and LOQ. ${ }^{18-20}$

\section{Determination of SMZ and TMP in the Suspension Preparation.}

The sample solution containing $6.1 \mu \mathrm{g} / \mathrm{ml}$ of SMZ and $17.2 \mu \mathrm{g} / \mathrm{ml}$ of TMP, and measure the absorption in the wavelength at 200-400 nm, then made AUC at spectrum (257-267) nm for SMZ and at (283-293) nm 
for TMP and calculated by UV Probe software 2.42 with a divisor of $17.2 \mu \mathrm{g} / \mathrm{ml}$ TMP for SMZ and 6.1 $\mu \mathrm{g} / \mathrm{ml} \mathrm{SMZ}$ as a divisor for TMP, and calculated with the following equation ${ }^{16-17}$ :

$$
\begin{aligned}
& A U C_{\lambda 1-\lambda 2}=X_{\lambda 1-\lambda 2}^{M} b C_{\lambda 1-\lambda 2}^{M}+X_{\lambda 1-\lambda 2}^{N} b C_{\lambda 1-\lambda 2}^{N} \\
& A U C_{\lambda 3-\lambda 4}=X_{\lambda 3-\lambda 4}^{M} b C_{\lambda 3-\lambda 4}^{M} b C_{\lambda 3-\lambda 4}^{N}
\end{aligned}
$$

Note:

$\mathrm{X}_{\lambda 1-\lambda 2}=\mathrm{AUC}_{\lambda 1-\lambda 2}$ concentration in $\mu \mathrm{g} / \mathrm{ml}$,

$\mathrm{X}_{\lambda 3-\lambda 4}=\mathrm{AUC}_{\lambda 3-\lambda 4} /$ concentration in $\mu \mathrm{g} / \mathrm{ml}$

$\mathrm{AUC}_{\lambda 1-\lambda 2}$ and $\mathrm{AUC}_{\lambda 3-\lambda 4}=$ Value of AUC for each component in a mixture

$\mathrm{X}^{\mathrm{M}}{ }_{\lambda 1-\lambda 2}$ and $\mathrm{X}^{\mathrm{M}}{ }_{\lambda 3-\lambda 4}=$ each absorptivity value from SMZ

$\mathrm{X}^{\mathrm{N}}{ }_{\lambda 1-\lambda 2}$ and $\mathrm{X}^{\mathrm{N}}{ }_{\lambda 3-\lambda 4}=$ each absorptivity value from TMP

$\mathrm{b}=$ thickness of cuvette $(1 \mathrm{~cm})$

$\mathrm{C}^{\mathrm{M}}$ and $\mathrm{C}^{\mathrm{N}}=$ concentration of component $\mathrm{SMZ}$ and TMP

\section{Chemometric Methods}

\section{Preparation An Absorption Spectrum}

The absorption spectrum at the concentration of working solution in $6.1 \mu \mathrm{g} / \mathrm{ml} \mathrm{SMZ}$ and $17.2 \mu \mathrm{g} / \mathrm{ml}$ TMP are measured at wavelengths of $230-310 \mathrm{~nm}$.

\section{Construction of Calibration Curves}

The Partial Least Squares value of SMZ and TMP absorption spectrum in the wavelength at230-310 nm is plotted with the concentration to get the regression equation.

\section{Determination of SMZ and TMP Levels in Suspension Preparations}

The sample solution containing $6.1 \mathrm{mg} / \mathrm{ml}$ of SMZ and $17.2 \mathrm{mg} / \mathrm{ml}$ of TMP, and measure the absorption spectrum of the partial least squares chemometric methods in the wavelength at $200-310 \mathrm{~nm}$ with intervals of $2 \mathrm{~nm}$. The calculated absorption value UV Probe 2.42 software with a divisor of $17.2 \mu \mathrm{g} / \mathrm{ml}$ TMP for SMZ and $6.1 \mu \mathrm{g} / \mathrm{ml} \mathrm{SMZ} \mathrm{as} \mathrm{a} \mathrm{divisor} \mathrm{for} \mathrm{TMP.}{ }^{6.21-22}$

\section{Determination of the Absorption Spectrum}

\section{RESULTS AND DISCUSSION}

The single-component of SMZ and TMP absorption spectrum curves are overlapped. The results in the overlapping absorption spectrum of SMZ and TMP (Fig.-1).

Based on Fig.-1, that the conventional ultraviolet spectrophotometry method cannot be used for determination of SMZ and TMP content in the mixture because the spectrum of the two substances overlaps, then the RA, AUC and CMS methods are applied to determine the content of a mixture can be done.

\section{Method of Validation}

The third method for assay spectrophotometry of SMZ and TMP validated by the validation parameters: accuracy, precision, detection limit and limits the quantity. ${ }^{16-18}$ In this study, the validation test was carried out by the standard addition method (Table-1).

Based on Table-1 above, it can be seen that the test results of validation parameters for the three methods have met the validation requirements of ICH guidelines 2015 so that all three methods have been valid for the assay of SMZ and TMP in the suspension. ${ }^{18-20}$

\section{Result of RA Methods}

Determination of intersection points by overlapping the maximum absorption curve of two substances. Based on Fig.-2, It's can be obtained that SMZ and TMP produce Intersection points at 2 points, namely at wavelengths of $249 \mathrm{~nm}$ and $271.8 \mathrm{~nm}$, but in this study an intersection point is used in the wavelength at $249 \mathrm{~nm}$ because it approaches the maximum absorption that meets the Lambert-Beer law and that point occurs before reaching the maximum wavelength of the two substances ${ }^{4-5}$. 
RASĀYAN J. Chem.

Vol. 12 | No. 4 |1693 - 1700| October - December | 2019

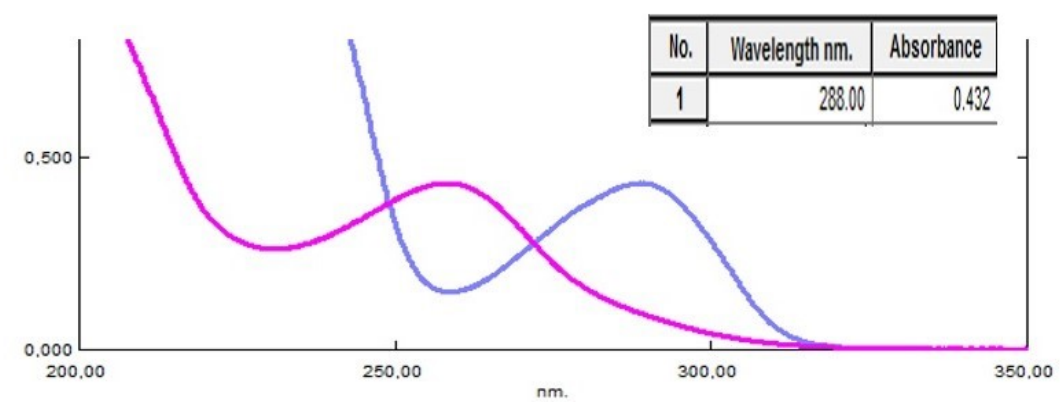

Fig.-1: Absorption Spectra Overlap of $6.1 \mu \mathrm{g} / \mathrm{ml} \mathrm{SMZ} \mathrm{and} 17.2 \mu \mathrm{g} / \mathrm{ml}$ TMP

Table-1: Validation Method Test of RA Methods, AUC, and CMS Methods

\begin{tabular}{c|c|c|c|c|c|c}
\hline \multirow{2}{*}{ Parameter } & \multicolumn{3}{|c|}{ SMZ } & \multicolumn{3}{c}{ TMP } \\
\cline { 2 - 7 } & RA & AUC & CMS & RA & AUC & CMS \\
\hline Spectrum & $249 \mathrm{~nm}$ & $257-$ & $230-$ & $249 \mathrm{~nm}$ & $283-$ & $230-$ \\
absorption & & $267 \mathrm{~nm}$ & $310 \mathrm{~nm}$ & & $293 \mathrm{~nm}$ & $310 \mathrm{~nm}$ \\
\hline Regression & $\mathrm{y}=0.063 \mathrm{x}-$ & $\mathrm{y}=.0232 \mathrm{x}$ & $\mathrm{y}=0.0711 \mathrm{x}$ & $\mathrm{y}=0.023 \mathrm{x}$ & $\mathrm{y}=0.0102 \mathrm{x}-$ & $\mathrm{y}=0.0252 \mathrm{x}$ \\
equation & 0.003 & -0.005 & +0.007 & -0.004 & 0.005 & +0.004 \\
\hline $\mathrm{R}^{2}$ & 0.9997 & 0.9978 & 0.9999 & 0.9995 & 0.9980 & 0.9999 \\
\hline Accuracy $(\%)$ & 99.89 & 99.34 & 100.69 & 101.28 & 100.05 & 101.25 \\
\hline Precision $(\%)$ & 0.20 & 0.44 & 0.44 & 0.71 & 1.16 & 0.43 \\
\hline LOD $(\mu \mathrm{g} / \mathrm{mL})$ & 0.2664 & 0.5164 & 0.0986 & 1.1744 & 1.7212 & 0.2143 \\
LOQ $(\mu \mathrm{g} / \mathrm{mL})$ & 0.8087 & 3.7247 & 0.3288 & 3.5588 & 12.4158 & 0.7142 \\
\hline
\end{tabular}

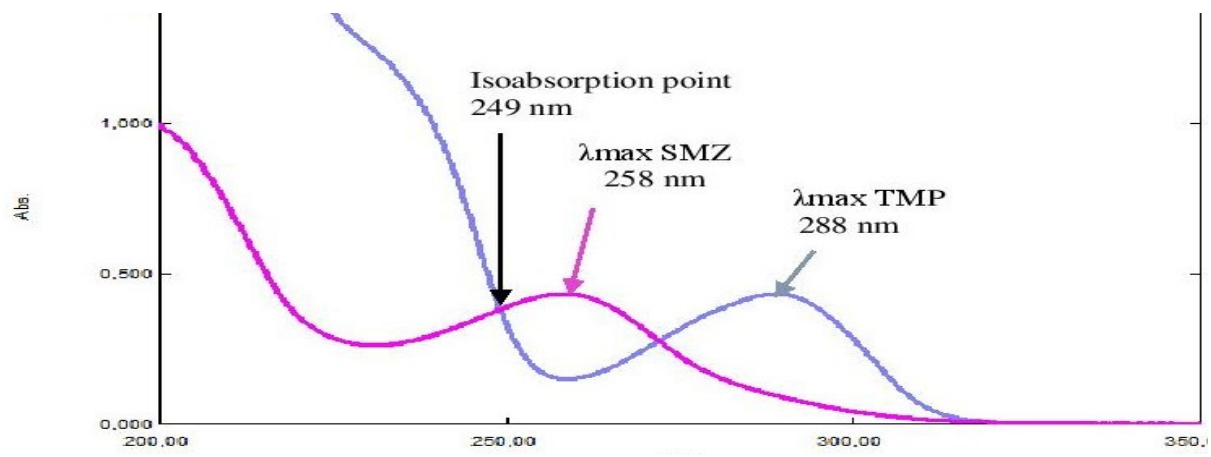

Fig.-2: Overlapping Results and Intersection Points

Determination of SMZ and TMP levels in Suspension Preparations

Determination performed an absorption spectrum at $249 \mathrm{~nm}$ and an absorption maximum of SMZ and TMP at $258 \mathrm{~nm}$ and $288 \mathrm{~nm}$ and the results of the calibration curve (Fig.-3).Based on the Fig.-3, it is shown that the SMZ has a regression equation at $249 \mathrm{~nm}$ is $\mathrm{Y}=0.063 \mathrm{X}-0.003$ and at $258 \mathrm{~nm}$ is $\mathrm{Y}=$ $0.071 \mathrm{X}+0.0000$ and has the same $\mathrm{r}^{2}$ value at 0.9999 as well as TMP has a regression equation at $288 \mathrm{~nm}$ is $\mathrm{Y}=0.025 \mathrm{X}+0.0000$ which and at $\lambda 249 \mathrm{~nm}$ is $\mathrm{Y}=0.022 \mathrm{X}+0.004$ which also has the same $\mathrm{r}^{2}$ value at 0.9999 , that means the RA method has good linearity. The calculated concentration of SMZ and TMP component is obtained by the formula the following mathematical equation:

$$
\begin{gathered}
C_{x}=\frac{Q_{m}-Q_{y}}{Q_{x} Q_{y}} x \frac{A}{a x 1} \\
C_{y}==\frac{Q_{m}-Q_{x}}{Q_{y}-Q_{x}} x \frac{A}{a y 1}
\end{gathered}
$$


RASĀYAN J. Chem.

Vol. 12 | No. 4 |1693 - 1700| October - December | 2019

The calculation results were obtained levels of SMZ and TMP in suspension preparations (Table-2).

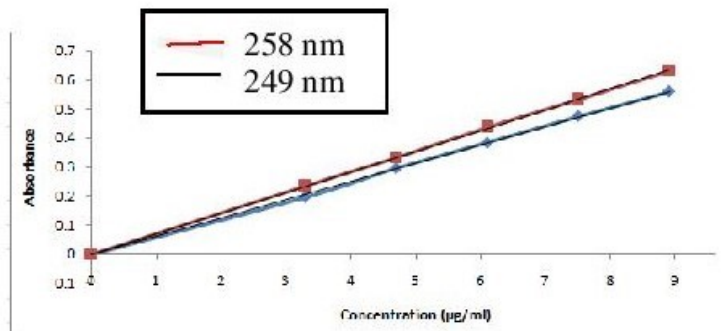

(a)

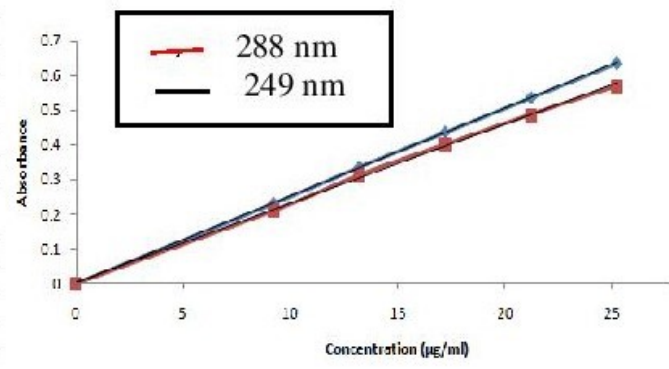

(b)

Fig.-3: RA Calibration Curve of (a) SMZ at $258 \mathrm{~nm} \mathrm{~nm}$ and $249 \mathrm{~nm}$ and

(b) TRI at $288 \mathrm{~nm}$ and $249 \mathrm{~nm}$

\section{Result of the AUC Method}

The AUC method is a method of conducting the assay with measuring and calculating the absorption area under the curve of the two wavelengths, at before and after the maximum wavelength of a drug component.

\section{Selected by Wavelength Area for AUC Method}

The wavelength of the SMZ and TMP analysis in the wavelength range for SMZ $(\lambda=257-267) \mathrm{nm}$ and TMP $(\lambda=283-293) \mathrm{nm}$. The selected wavelength range is to provide linearity with the value of the correlation coefficient value of $\leq 1$. It means this method has an excellent method because it has linearity $\leq 1$ (Table 1) and the following equation calculated the component:

$$
\begin{aligned}
& A_{1}(\lambda 1-\lambda 2)=a(\lambda 1-\lambda 2) C_{s}+a(\lambda 1-\lambda 2) C_{T} \\
& A_{2}(\lambda .3-\lambda 4)=a(\lambda .3-\lambda .4) C_{s}+a(\lambda .3-\lambda 4) C_{T}
\end{aligned}
$$

Note:

$\mathrm{A}_{1}=$ AUC value of mixture at range $\lambda=257-267 \mathrm{~nm}$

$\mathrm{A}_{2}=$ AUC value of mixture at range $\lambda=283-293 \mathrm{~nm}$

$\mathrm{C}_{\mathrm{S}}=$ concentration $\mathrm{SMZ}$

$\mathrm{C}_{\mathrm{T}}=$ concentration $\mathrm{TMP}$

The AUC results of each drug at the maximum absorption of SMZ and TMP can be the calculation of the concentration of components with the following equation:

$$
\begin{aligned}
& A_{1}=0.0252 C_{s}-0.0083 C_{T} \\
& A_{2}=0.00377 C_{s}+0.01017 C_{T}
\end{aligned}
$$

Then the use of equation 1 and equation 2 above can be calculated the values of $C s$ and $C_{T}$ with mathematical solutions.

\section{The Determination Result of SMZ and TMP Levels in Suspension Preparation}

The sample has been prepared, then measured in the wavelength at 200-400 nm. The absorption spectrum of the samples obtained is a mixture of SMZ and TMP spectrums to get Area Under Curve values in the area 257-267 for SMZ and TMP divisor and 283-293 for TMP with SMZ divisor (Fig.-4), and calculated using the regression equation (Table.-1), and statistical calculations (Table.- 2). The levels of SMZ and TMP were obtained in the suspension form, and after performing the statistical calculation (Table-2) is $99.94 \pm 1.3696 \%$ for SMZ and $99.03 \pm 1.5749 \%$ for TMP and fulfill the requirements in the Indonesian Pharmacopoeia $5^{\text {th }}$ edition. $^{4}$

\section{Result of Chemometrics Methods}

Partial least squares (PLS) are one type of multivariate calibration of the chemometric method used to process data because it is able to produce a calibration model with a good predictive ability for large amounts of data. Regression analysis from SMZ and TMP can be seen in Table-1 and Fig.-5.

The absorption spectrum of the sample is measured to get 41 sets of data absorption ef with prepared as by a calibration model for data of partial least square value of chemometric, value and get 41 sets of data 
RASĀYAN J. Chem.

Vol. 12 | No. 4 |1693 - 1700| October - December | 2019

absorption of with prepared as by a calibration model. The selected wavelength range is the range provides of the best linear relationship between the PLS and concentration as indicated by the correlation coefficient $\leq 1$ (Table-1). The concentration where the absorbance obtained fulfill the law of Lambertbeer in the range of 0.2-0.6 and calculated levels obtained then performed statistical calculations ${ }^{22}$.

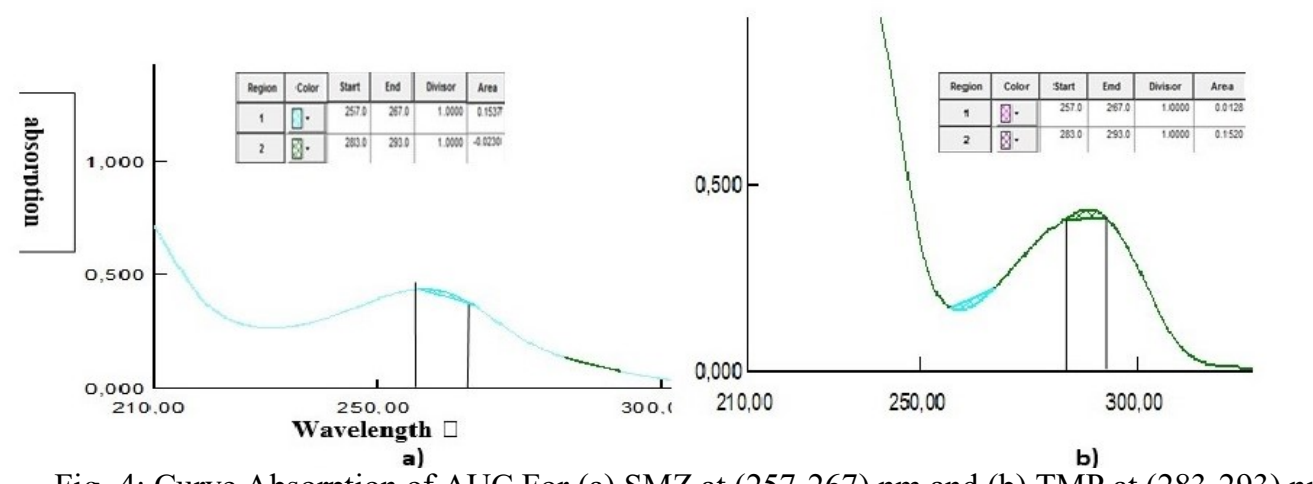

Fig.-4: Curve Absorption of AUC For (a) SMZ at (257-267) nm and (b) TMP at (283-293) nm
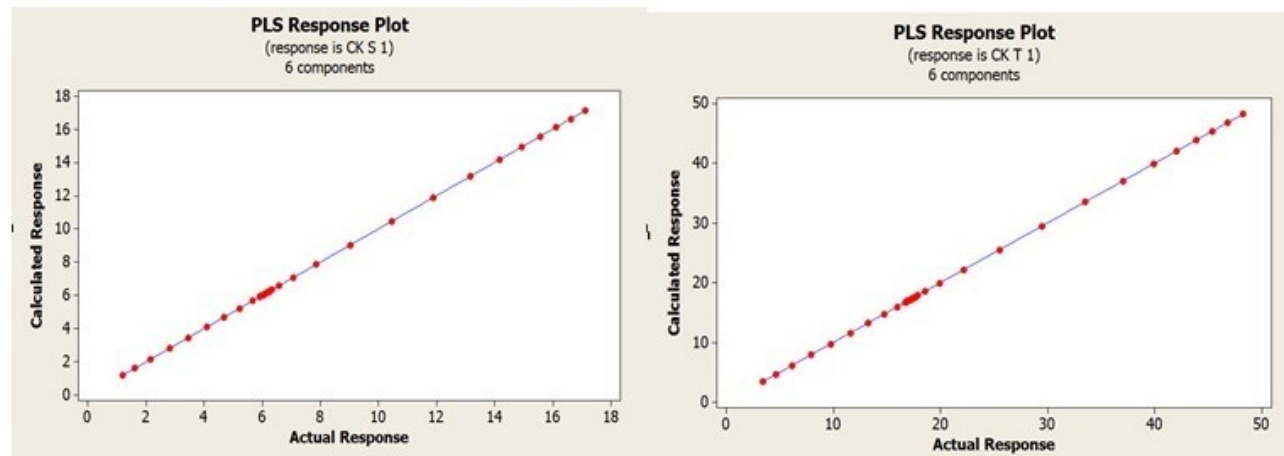

Fig.-5: Curve of PLS Response Plot of (a) SMZ and (b) TMP at 230-310 nm with Interval $2 \mathrm{~nm}$

\section{Result of Statistic Calculation of RA, AUC and CMS Methods}

The result of calculation statistic each of SMZ and TMP content can be seen in Table-2 below:

Table-2: Statistic Calculation of SMZ and TMP

\begin{tabular}{c|c|c|c|c}
\hline Component (\%) & RA & AUC & CMS & Requirements \\
\hline SMZ (\%) & $99,64 \pm 0,28$ & $99.94 \pm 0.37$ & $98,66 \pm 0,0105$ & $90-110$ \\
\hline TMP (\%) & $96,80 \pm 0,74$ & $99.03 \pm 0.57$ & $98,12 \pm 0,0051$ & $90-110$ \\
\hline
\end{tabular}

Based on Table-2, can be seen that the three analytic methods of ultraviolet spectrophotometry have levels that meet requirements according to the $4^{\text {th }}$ edition of the Indonesian pharmacopeia monograph. It means that the three methods can use for the determination simultaneous of SMZ and TMP mixture in a suspension dosage form.

\section{CONCLUSION}

The spectrophotometry method by ratio absorption methods, the area under curve method, and chemometric method can be applied for the determination of the levels of SMZ and TMP in suspension preparations because they have fulfilled the validation requirements with accuracy, precision, linearity, LOD, and LOQ parameters. The ratio absorption methods, the area under curve method, and chemometric method, although have a difference in procedures, regression equation, and wavelength measurements, but the levels obtained appropriate the requirements. The ratio absorption methods, the area under curve 
method, and chemometric method is a simple, practical, easy to implement, and economical method by using efficient mathematical software to determination sulfamethoxazole and trimethoprim mixture.

\section{ACKNOWLEDGMENT}

The authors like to acknowledge Dean and research laboratory, Faculty of Pharmacy, Universitas Sumatera Utara, Medan, Indonesia on laboratory facilities to carry out the research work.

\section{REFERENCES}

1. T.H.Tjay, and K. Rahardja, 2007, Important Medicine: Efficacy, Use and Side Effect, $6^{\text {th }}$ ed Jakarta, PT Elex Media Komputindo.

2. B.Katzung, A.Trevor, and S.Masters, 2008, Pharmacology Examination and Board Review, New York: Mc Graw Hill.

3. A. C. Moffat, M. D.Osselton, B. Widdop and L.Y.Galichet, 2011, Clarke's Analysis of Drugs and Poisons. $4^{\text {th }}$ ed. London: Pharmaceutical Press, p.507-515

4. Indonesian Health Ministry, Indonesian Pharmacopoeia, $5^{\text {th }}$ ed., Director General of Health Care and Medical Devices, p. 523-525, 769(2014).

5. J. Mamatha and N. Devanna, Rasayan Journal of Chem., 11(2), 452(2018), DOI:10.31788 /RJC. 2018.1122079

6. A. H. Kamal, S. F. El-Malla and S.F. Hammad, EJPMR., 3, 348(2016).

7. G. Singh, D. Kumar, D. Sharma, M.Singh and S. Kaur, J. App. Pharm. Sci., 2, 222(2012), DOI: 10.7324/JAPS.2012.2736.

8. M. Bachri, J. Reveny, Y. M.Permata and C. E. A. Situmorang, Rasayan J. Chem., 12(1), 232, (2019), DOI: 10.31788/RJC.2019.1215013

9. K. Harinadha Baba, C.Rambabu, Riyaz Ahmed Khan, and K. Anil Kumar, Rasayan Journal of Chem., 7(4), 359(2014)

10. G. Pandey, M. Brameshwar and M. ISRN, Spectroscopy, 5 pages. (2013), DOI:10.1155 /2013/912376

11. A. Rohman, S. Diana, Sudjadi and R. Sugeng, J. Med. Sci, 15, 178(2015), DOI:10.3923 /jms. 2015.178.184

12. S.A.Nada, Arabian J. Chem., 9, S355(2016), DOI:10.1016/j.arabjc.2011.05.0021878-5352 a 2011

13. M. Bachri, R. P. Tuty and R. Edward, AJCPR, 11(12), 344(2018), DOI:10.22159/ajpcr.2018. v11i12.28093

14. M. R. Khoshayand, H. Abdollahi, M. Shariatpanahi, A.Saadatfard, and A Mohammadi, Spectrochimica Acta: Part A Molecular and Biomolecular Spectroscopy, 70, 491(2008), DOI: 10.1016 / J. Saa. 2007;07.033

15. K. Abdel, S. M. Attia, N. M. Abasawy and A. M. Abdelraool, WJPPS, 5, 214(2016), DOI: 10.20959/wjpps20164-6339.

16. K. A. M. Attia, N. M. Elabasawy and E. Abolmagd, Fut. Jour. of Pharm.Sci, 30,12017), DOI: 10.1016/j.fjps.2017.06.001 10.1016/j.fjps.2017.06.001

17. S.R. Karajgi, A.R Tanveer and N.V. Kalyane, J. Pharm. Sci. \& Res., 8, 506(2016).

18. U.S. Food and Drug Administration, 2015.

19. J. Ermer and J. H. Miller, 2005, Method Validation in Pharmaceutical Analysis. A Guide to Best Practice. Weinheim: Wiley-Vch Verlag GmBH \& Co. KGaA; 171.

20. F. Harmita, MIK, Jakarta, 1(3), 118(2004).

21. E.Hismiogullari, E.Yarsan E, Hacettepe University Journal of the Faculty of Pharmacy, 29, 96(2009)

22. J.N. Miller and J.N.Miller, Statistic and Chemometrics for Analitical Chemistry, Sixth edition. Harlow: Pearson Education, 238, 243 (2010).

[RJC-5428/2019] 